\title{
Epidemiología de las infecciones del tracto urinario en niños y riesgo de recurrencia y alteraciones nefrourológicas
}

\author{
Rosanna Lagos Z. ${ }^{\text {; }}$ Jenny Carter S. ${ }^{\text {; }}$ Carmen Benavente R. ${ }^{1}$; \\ Tamara Lamberg I. ${ }^{1}$; Alma Muñoz M. ${ }^{1}$; Inés Bravo R. ${ }^{2}$; José Campos S. ${ }^{1}$; \\ Gloria Soto G. ${ }^{i}$; Patricio Herrera L. ${ }^{2.3}$ \begin{abstract}
abnormalities in children with urinary tract infections
\end{abstract} \\ Epidemiology and risk factors for recurrences and nephrourologic
}

\begin{abstract}
From march 1992 to Eebruary 1993, the Ministry of Health of Chile sponsored a program intended to improve medical core and gather epiderniclogic information on urinary tract infections in the pediatric population served by the Northern Son-iago Metropolitan Health Service ISSMM! During this period, suspicious cases of urinary tracl infections [UTI\} fresenting at severi (out o: 14) ambulalory care cenlers and al the lacal pediatric hospital emergency room were refer'ed to a special unit i j'T elinicj al that same hospital, where diognoses were confirmed and patients were treated and followed by a standord protocol, including rencl ultrasonogram and voiding cystourethrography to all patients without previous radiologic evaluation. By the lime of this study the SSMN cored for 188329 children lage under 15 vearst, 108221 of therr. were adscribed to the participating health centers, and 1.275 palients were referred to the UTI clinic, 630 being confirmed UTI cases The attack rate of the disease was significantly higher in the participating healt? centers $[3.7 \% 1.000$, tha: : n the non porticipoling ones $12.7 / 1.000 . \mathrm{p}<0.0003$ ). Acute pyelonephritis was significantly mose common in children under 24 months of age then among other ages: $O R=3.3\langle| C O 5 \%=2,1-5,3\}$; $p<0.0000001$. E. cofi was the predominant basterial pathogen in males and femoles, but identification of non $E$. coli baclerioe was significontly more freqtent among male patients $(O R=17,3 ; \| C 95 \%=8.0-38.0)$. Five hundred and twenty two children were followed beyond recovery of the index UTI and 148 had at least a second episode of UTI during the folow-Jp period 11 to 18 months, median and mode 6 monthst: $87,8 \%$ of the delected recurrences occurred before the seventh month of followup. Age 24 to 71 months and non $E$. coli infections were associated with significanty higher risk. of recurrences: $O R=2.5 ;: I C 95 \%=1.5-4.0)$ and $O R=2.5$ (iC $95 \%=1,2.5,21$, respeclively. Mole patieris ond those with acute pyelonephitis were of significantly higher risk of bearing morphologic abnormalities: $O R=2,0, \mathbb{K C} 95 \%=1.03-3,9 !$, and $O R=2,0 ; \operatorname{KC} 95 \%=1,2-3,51$.
\end{abstract}

'Key words: usinary trast infections, epidemiolegy, risk faclors.|

Las infecciones del tracto urinario (infección urinaria) son de elevada incidencia y prevalencia y afectan a individuos de todas las edades, sin predilección geográfica ni por estratos socioeconómicos $^{14}$. Aunque la mayoría de las infecciones urinarias tienen comportamiento clínico benigno y pronóstico favorable, en el niño pueden constituir la primera expresión clínica

1. Hospital Roberto del Río, Servicio de Salud Metropolitano Norte.

2. Departamento de Pediatría, Facultad de Medicina, Campus Norte, Universidad de Chile

3. Centro de Epidemiología Clínica, Facultad de Medicina Campus Norte, Universidad de Chile. de anomalías anatómicas o funcionales de las vías urinarias que requieren tratamiento médico o quirúrgico especializado ${ }^{1-4}$; además, los seguimientos de individuos con infecciones urinarias durante la infancia revelan, en cierta proporción de ellos, recurrencias, cicatrices renales, hipertension arterial o insuficiencia renal crónica ${ }^{1-7}$. En consecuencia, estas infecciones son un problema de salud pública que debe ser enfrentado con estrategias basadas en conocimiento de la epidemiología local, para determinar la cuantía y calidad de recursos que demanda la asistencia inmediata de los enfermos con infección urinaria y para identificar a los individuos en los cua- 
les es necesario concentrar recursos complejos de diagnóstico y tratamiento.

En 1990 se revisó retrospectivamente una serie de episodios de infección urinaria ocurridos en niños beneficiarios del Servicio de Salud Metropolitano Norte (SSMN) ${ }^{8}$. Dicha revisión mostró deficiencias en el diagnóstico, tratamiento y seguimiento de estos enfermos y la necesidad de realizar estudios prospectivos para hacer el diagnóstico epidemiológico. El Ministerio de Salud (PMU/APS-AD) aprobó un programa para mejorar la calidad de la atencion médica de los niños con infección urinaria en el SSMN y obtener información aplicable a la planificación de su atención primaria, secundaria y terciaria en el país. El programa incluyó la derivación (transitoria) de los casos sospechosos pesquisados en centros de atención primaria y de urgencias del Servicio a una unidad asistencial para tal propósito, en la que se aplicaron protocolos de estudio, tratamiento y seguimiento. Paralelamente, se desarrolló un conjunto de actividades de capacitación teórica y práctica dirigidas a los médicos a cargo de la atención pediátrica primaria.

La presente comunicación da cuenta de la información epidemiológica recopilada durante este programa, e incluye un análisis de sexo ${ }^{9}$, edad $^{10}$, nivel anatómico ${ }^{11}$ y agente etiológico) ${ }^{12.13}$, factores tradicionalmente considerados de riesgo de recurrencias o complicaciones nefrourológicas subyacentes en niños con infección urinaria. Ella constituye la base de otros estudios, actualmente en curso, donde se analiza la influencia de algunos marcadores genéticos (grupos sanguíneos) y factores de virulencia bacterianos, sobre los eventos clínicos.

\section{Pacientes y Método}

Clínica de infección urinaria. En el Hospital Roberto del Rfo del SSMN se habilitó una unidad clínica para atención inmediata de todos los pacientes con sospecha infec. ción urinaria pesquisados en consultorios periféricos y en la unidad de emergencias del hospital. La clínica de infección urinaria funcion 6 de lunes at viemes, de 8,30 a 18,00 horas, atendida por un médico, un auxiliar de enfermería y un tecnólogo médico, con los materiales necesarios para obtener y procesar muestras de orina y proteína $\mathrm{C}$ reactiva.

Pesquisa y referencia de pacientes. Antes de iniciar el programa se acord6, en 7 de los 14 consultorios del servicio, así como en las unidades de internacion y de emergencias del Hospital Roberto del Río, que se derivarfa de in- mediato a la clínica de infección urinaria a los nifios que consultaran con síntomas compatibles con infección urinaria alta o baja (disuria, polaquiuria, tenesmo, urgencia, ardor a dolor miccional, dolor lumbar esponłáneo o puño percusión dolorosa y enuresis secundaria); fiebre de causa no aclarada por la anamnesis o el examen físico, sin sintomas de vía urinaria (se enfatizó la aplicación de este criterio en menores de 2 anos y se promovió restringir el uso de antimicrobianos de efecto sistémico, en pacientes sin diagnóstico claro); cualquier otro motivo de sospecha de infección urinaria, a juicio del medico (incremento ponderal deficiente, inapetencia, alteraciones del aspecto de la orina); infección urinaria tratada en los tres meses precedentes, sin seguimiento posterior. En los sitios de pesquisa se distribuyeron copias de un formulario de derivación, en el que se solicito registrar la identificación del médico y el paciente, el criterio de sospecha aplicado y los antecedentes anamnésicos más relevantes.

Evaluación inicial. La evaluación inicial de cada nirfo referido incluy 6 anamnesis, examen físico, examen quimico y microscópico de orina y urocultivo. En los pacientes cuya evaluación resulto en "sospecha de infección urinaria" (definición más adelante), se hizo, ademås, una determinación cuantitativa de protę́na $C$ reactiva. Tan pronto se obtuvo el informe bacteriologico, el resultado de Ja evaluacion clínica y de laboratorio fue comunicado por escrito al nßedico que derivó al paciente. El manejo en la clínica de infección urinaria se ajustó a normas técnicas y definiciones convencionales ${ }^{14}$, adaptadas a las condiciones locales vigentes. Se usaron las siguientes denominaciones: sospecha de infección urinaria (alta o baja) a los síntomas atribuibles a infección urinaria alta o baja más leucocituria igual o mayor a $10 / \mathrm{mm}^{3}$, en muestra de orina no centrifugada; bacteriuria significativa el hallazgo de germen Gram negativo único, en recuento igual o mayor a 105 unidades formadoras de colonia por $\mathrm{ml}$ (UFC/ml); infección urinaria al urocultivo positivo a germen único, en recuento mayor o igual a $105 \mathrm{UFC} / \mathrm{ml}$, asociado a leucocituria igual o mayor a $10 / \mathrm{mm}^{3}$. Se denominó pielonefritis aguda (PNA o infección urinaria alta) a la infección urinaria acompañada de, al menos, dos de los siguientes hallazgos: antecedente anamnésico o comprobación de fiebre mayor o igual a $38.5^{\circ} \mathrm{C}$ rectal, puño percusión lumbar dolorosa o vómitos, proteína C reactiva mayor de $20 \mathrm{mg} / \mathrm{dl}$. Las infecciones urinarias sin elementos de pielonefritis se consideraron bajas. Bacteriuria asintomática: Bacteriuria significativa, con leucocituria inferior a $10 / \mathrm{mm}^{3}$, en dos muestras de orina obteridas en un plazo inferior a 5 dias sin mediar tratamiento, en pacientes afebriles y sin sintomatología urinaria. Se definio como infección urinaria previa la de nínos enviados con historia de infeccion urinaria tratada y fueron ingresados al protocolo de estudio y seguimiento (ver más abajo), aunque la evaluación inicial arojara resultados negativos, siempre que se adjuntaran los resultados del estudio bacteriológico del episodio, éste hubiese ocurrido en un plazo no anterior a tres meses a contar de la referencia, el paciente no hubiese side previamente controlado ni estudiado en la Unidad de Nefrourología del Hospital Roberto de] Rio u otro centro similar. Estos casos fueron catalogados como "infección urinaria previa".

Las muestras de orina fueron obtenidas en la mitad de la micción, después de aseo riguroso de la zona genital con agua y jabón antiséptico. En los nitos sin control 
esfinteriano se instalo un recolector de plástico por un tiempo máximo de $\mathbf{4 5}$ minutos, y se practic 6 aspiración suprapúbica cuando no hubo emisıón de orina en ese plazo. Previo al inicio del tratamiento, se indicó repetir el estudio urinario en todos los nifos con bacteriuria significativa sin leucocituria y en los pacientes con sospecha de PNA

El tratamiento de elección fue el ambulatorio y por vía oral. En los niños con sospecha de pielonefritis aguda se inició con cefalosporinas orales el mismo día de la consulta, después de obtenida la segunda muestra de orina. En las infecciones urinarias bajas, salvo aquéllas nuy sintomáticas, se indico trataniento una yez obtenido el resultado del estudio de sensibilidad, preferentemente con nitrofurantoina. El tratamiento se mantuvo durante 10 días en las pielonefritis y 7 en las infecciones bajas; en ambos casos se efectuó un control bacteriológico 24 a $72 \mathrm{~h}$ después de iniciarlo y otro tres a cinco días después de terminarlo. En los niños con malformaciones, alteraciones funcronales de las vías uninarias o recurrencias durante el seguimiento se indicó profilaxis con nitrofurantóna en dosis única noctuma.

Las muestras de orina, sembradas en medio selectivo y no selectivo antes de 15 minutos desde su obtención, fucron enviadas al laboratorio de bacteriología del hospital para el estudio de rutina. Inmediatamente después de la siembra se efectú análisis químico con tira reactiva (Combur 9, Boeringher-Mannheim) y examen microscopico de la muestra no centrifugada, en cámara de Neubahuer. En los casos de sospecha de infección urinaria se obtuvo una muestra de sangre por punción capilar para determinación cuantitativa de proteína $C$ reactiva con el método nefelométrico (Orion Diagnostica, Finlandia). Los resultados del examen directo de orina y de dicha proteína fueron informados de ínmediato al médico, a fin de complementar la evaluación clínica del paciente.

En los niffos con infección urinaria confirmada en la evaluación inicial y los que cumplian con el criterio para diagnosticar infeccion urinaria previa se indicó un programa de estudio y seguimiento con evaluaciones médicas y exámenes de orina mensuales y ultrasonografía abdominal (ECO) y uretrocistograffa miccional seriada (CUMS). Además, los pacientes fueron estimulados a consultar espontáneamente a la clínica de infección urinaria si presentaban fiebre o molestias urinarias. Los niños beneficiarios de otras areas de salud y los que habían sido previamente estudiados en la unidad de nefrourologfa del bospital fueron tratados y controlados hasla confirmarse la curación bacteriológica del episodio y posteriormente fueron referidos al cencro asistencial pertinente.

Los pacientes cuyo estudio radiologico era normal y no tuvieron recurrencias en seis meses de seguimiento fueron derivados a su consultorio de origen, con indicacion de coninuar con controles de orina cada dos meses durante un año. Los que sufrieron recurtencias o tenían alteraciones anatómicas o funcionales de la vía urinaria en el estudio por imágenes fueron derivados a la unidad de nefrourología.

La identificación, la información clínica de cada paciente referido a la clínica de infección uribaria y el seguimiento posterior de los casos confirmados fueron regisirados en un formulario diseñado para este fín. La información del formulario fue codificada y traspasada a un archivo computacional, en un programa EpiINFO 5.0.
Durante el desarrollo del programa se revisaron periódicamente los libros de egresos de las unidades clínicas del hospital, con el fin de identificar las hospitalizaciones cuya causa primaria fue infección urinaria. A partir de ellas se analizaron las fichas clinicas correspondientes y se completó un registto individual que incluyó datos de identificación y procedencia (consultorio de origen) del paciente.

En 7 de los 14 consultorios del SSMN se mantuvo el mecanismo habitual de atención de pacientes con sospecha de infección urinaria, que a la fecha incluia el procesamiento de las muestras de orina en el laboratorio del Hospital Roberto del Río. Los registros del laboratorio fueron usados para pesquisar los episodios de infección urinaria diagnosticados en los consultorios cuya población no estuyo directamente adscrita al programa; en estos casos se consideró episodio de infección urinaria a los exámenes con bacteriuria significativa asociada a leucocituria $\geq 10 / \mathrm{mm}^{3}$.

Con fines descriptivos se utilizaron promedios y proporciones; los datos de dispersión se expresaron en desviaciones estándar e intervalos de confianza. La asociación entre variables independientes (edad, sexo, agente etiológico y nivel anatomico de la infeccion urinaria) y los eventos de interés clínico (tecurrencias y alteraciones nefrourológicas) fueron estudiados calculando razones de disparidad o ventaja (OR). El efecto de la combinación de variables independientes sobre las variable dependientes se investig6 mediante análisis estratificado". En el análisjs de significación estadística se aplicó pruebas de Chi cuadrado y Fisher; el nivel de significación se preestableció en $5 \%$.

\section{Resultados}

Tasas de infección urinaria ambulatoria y de hospitalizaciones por infección urinaria. En el año 1992 la población menor de 15 años del SSMN era de 188329 habitantes. 108221 niños estaban asignados a los siete consultorios que refirieron sus pacientes sospechosos a la clínica de infección urinaria y 80118 pertenecían a los siete restantes. Entre marzo de 1992 y febrero de 1993 la unidad atendio 1275 referencias; 970 de ellas eran pacientes derivados desde los consultorios del SSMN; 242 eran niños enviados desde la unidad de emergencia y $63 \mathrm{pa}$ cientes egresados de las unidades de internación del hospital. En 555 de los pacientes se comprobó infección urinaria en la evaluación inicial y otros 75 cumplieron con los criterios de infección urinaria previa (la incidencia de infección urinaria activa al momento de la referencia aquí reportada $(43,5 \%)$ difiere de la informada en una publicación previa $(35,15 \%)^{16}$, lo que obedece a la inclusion, en el estudio anterior, solo de pacientes que no habían recibido antimicrobianos y cuya muestra de orina fue obtenida y procesada en la clínica de infección urinaria, 
mientras éste incluyó todos los pacientes referidos.

El total de pacientes referidos y los niños con diagnóstico confirmado difirieron significativamente, en edad y sexo, de la población pediátrica beneficiaria del SSMN; en consecuencia, las tasas de ataque de la enfermedad variaron en función del sexo y los diferentes estratos etareos de este servicio. En las niñas, las tasas fluctuaron desde 4,73/1 000, en mayores de 71 meses, hasta 6,03/1000, en menores de 24 meses. En varones, las tasas por categorías de edad declinacon desde $2,69 / 1000<24$ meses, hasta 0,34 l $1000>71$ meses.

Quinientos setenta y tres (573) de 630 episodios de infección urinatia fueron diagnosticados y tratados en forma ambulatoria y los otros 57 requirieron hospitalización en algún momento de la evolución de la enfermedad. De los episodios ambulatorios, 23 sucedieron en pacientes de la unidad de nefrourología; 27 en beneficiarios de otros servicios de salud; 403 ocurrieron en niños de los 7 consultorios adscritos al programa y 120 en pacientes de los consultorios no adscritos. Excluidos los episodios ocurridos en pacientes de la unidad de nefrourología y de sectores ajenos al SSMN, la tasa de infección urinaria ambulatoria (calculada en base al total de episodios atendidos en la clínica de infección urinaria en la población adscrita) fue de 3,7/ $1000<15$ años. En la población no adscrita, los casos derivados a la clínica de infección urinaria desde la unidad de emergencias $(n=120)$, sumados a 100 episodios pesquisados en los registros del laboratorio del Hospital Roberto de] Río, sugieren una incidencia (estimada) de infección urinaria ambulatoria notablemente inferior $(2,7 / 1000<15$ años; $\mathrm{p}=0,0003)$. La vigilancia de egresos en el mencionado hospital revelo cifras similares por infección urinaria en las poblaciones adscritas y no adscritas al programa (26 y 25 egresos, respectivamente). Sin embargo, el riesgo de hospitalización para los pacientes con infeccion urinaria tue tres veces más alto el año 1990 que durante el funcionamiento de la clínica de infección urinaria (94 hospitalizaciones sobre 456 diagnosticos en 1990 , ante 51 hospitalizaciones sobre 674 diagnósticos en 1992 [OR $=3,17$; (IC 95\% $=2,2$. $4,7) ; \mathrm{p}<0,00001]$. Así mismo, en 1992 el riesgo de hospitalización de los pacientes con infección urinaria fue cercano al doble en la población no adscrita, con respecto a la adscrita al programa. En la tabla 1 se exponen los datos de incidencia para el período marzo de 1992 a febrero de 1993, en contraste con lo observado

Tabla 1

Incidencia de infeccion del tracto urinario en los niños beneficiarios del Servicio de Salud Metropolitano Norte (SSMN) ${ }^{1}$, en dos periodos con diferente mecanismo de pesquisa

\begin{tabular}{|c|c|c|c|c|}
\hline & $\begin{array}{c}\text { Población } \\
\text { adscrita } \\
\text { n = } 108221\end{array}$ & $\begin{array}{c}\text { Población no } \\
\text { adscrita } \\
\text { n= } 80118\end{array}$ & $\begin{array}{c}\text { Poblacjón <15 años } \\
\text { SSMN }-1992 \\
\text { n }=188339\end{array}$ & $\begin{array}{c}\text { Población }<15 \text { años } \\
\text { SSMN }-1990 \\
\text { n }=183977^{3}\end{array}$ \\
\hline $\begin{array}{l}\text { Casos atendidos en la } \\
\text { clínica de TTU }\end{array}$ & 403 & $120^{4}$ & 523 & \\
\hline $\begin{array}{l}\text { Casos pesquisados en } \\
\text { registros de laboratorios }\end{array}$ & & 100 & 100 & 181 \\
\hline $\begin{array}{l}\text { Tasa de ITU ambulatoria } \\
\text { (/1 } 000<15 \text { años })\end{array}$ & 3,7 & 2,7 & 3,3 & 2,0 \\
\hline Hospitalizaciones por 1TU (n) & 26 & 25 & $51^{6}$ & $94^{7}$ \\
\hline
\end{tabular}

ITU: infección de la vía urinaria.

1. Se excluyen los casos ocurridos en pacientes controlados en la unidad de nefrourologia.

2. Población asignada a siete consultorios, que derivaron los casos sospechosos a la clínica especial.

3. Datos extrapolados a partir de una revisión de un semestres

4. Corresponde a casos derivados desde la unidad de emergencias del mismo hospital.

5. Urocultivos con recuento igual o mayor a $105 \mathrm{UFC} / \mathrm{ml}$, asociados a leucocituria igual o mayor a $10 / \mathrm{mm}^{3}$, en libros de laboratorio del hospiral.

6 vs 7, OR $=3,17:($ IC $95 \%=2,2-4,7) ; p<10^{-6}$. 
en la totalidad de la población pediátrica del SSMN en la revisión retrospectiva del año 1990.

Frecuencias de confirmación de infección urinaria según motivos de sospecha clínica. $\mathrm{El}$ criterio de sospecha aplicado al derivarlos, permitió clasificar a los pacientes en cuatro grupos. Grupo A: $(n=697)$, algún síntoma atribuible a inflamación de la vía urinaria alta o baja; Grupo B: $(n=308)$, fiebre de causa no aclarada por la anamnesis o el examen físico; Grupo $\mathrm{C}$ : $(\mathrm{n}=$ 199), otros motivos de sospecha de infección urinaria (mal incremento ponderal, alteraciones del aspecto de la orina, anorexia, dolor abdominal recurrente, etc), y Grupo D: $(n=71)$, asintomáticos, con documentación de infección urinaria previa y sin seguimiento posterior. El criterio de sospecha de infección urinaria, en combinación con la edad y sexo de los pacientes, determinaron una gradiente de frecuencias de confirmación de la sospecha clínica. En contraste con Io esperado, la mayor frecuencia de confirmacion de infección urinaria no ocurrió entre pacientes sintomáticos (grupo A), sino entre los derivados por infección urinaria recientemente tratada. Las derivaciones por fiebre también alcanzaron un grado notable de confirmación de la sospecha clínica, especialmente en el grupo de menores de 2 años (tabla 2).

Distribución de formas clínicas. La tabla 3 muestra la distribución de categorías por diagnóstico, resultante de la evaluación clínica y de laboratorio en los pacientes referidos. Nuevamente, la estratificación por edad y sexo determinó diferencias significativas en la representación de las formas clínicas. La pielonefritis aguda fue la más frecuente entre los menores de 24 meses, mientras en todas las demás edades predominó la localización baja, en niñas y niños. El riesgo de pielonefritis aguda, excluyendo los ca-

Tabla 2

Frecuencia de confirmación diagnóstica según motivo de la sospecha clínica de infección urinaria, edad (en meses) y sexo de los pacientes

\begin{tabular}{|c|c|c|c|c|c|c|c|c|}
\hline & \multicolumn{2}{|c|}{$\begin{array}{c}0 \text { a } 23 \\
\text { Total }=292\end{array}$} & \multicolumn{2}{|c|}{$\begin{array}{c}24 \text { a } 47 \\
\text { Total }=288\end{array}$} & \multicolumn{2}{|c|}{$\begin{array}{c}48 \text { a } 71 \\
\text { Total }=185\end{array}$} & \multicolumn{2}{|c|}{$\begin{array}{c}>=72 \\
\text { Total }=439\end{array}$} \\
\hline & $\mathbf{v}$ & $\mathbf{M}$ & $\mathbf{v}$ & $\mathbf{M}$ & $\mathbf{V}$ & $\mathbf{M}$ & $\mathbf{V}$ & $\mathbf{M}$ \\
\hline \multicolumn{9}{|l|}{ Grupo A: $(n=697)$} \\
\hline Número de pacientes teferidos & 11 & 26 & 49 & 147 & 19 & 117 & 48 & 280 \\
\hline Número de casos confinmados & 3 & 13 & 25 & 87 & 10 & 80 & 14 & 203 \\
\hline$\%$ de casos confirmados & 27.3 & 50,0 & $5 t, 0$ & $\$ 9,2$ & 62,8 & 83,4 & 29,2 & 72,5 \\
\hline \multicolumn{9}{|l|}{ Grupo B: $\{n=308\}$} \\
\hline Númera de pacientes referidos & 46 & 113 & 21 & 34 & 8 & 24 & 19 & 43 \\
\hline Número de casos confirmados & 15 & 35 & 4 & 8 & 1 & 10 & 1 & 26 \\
\hline$\%$ de casos confirmados & 32,6 & 31.0 & 19,1 & 23.6 & 12.5 & 41,8 & 5,3 & 60,5 \\
\hline \multicolumn{9}{|l|}{ Grupo $C:(n=199)$} \\
\hline Número de pacientes referidos & 29 & 67 & 14 & 23 & 2 & 15 & 21 & 28 \\
\hline Número de casos confirmados & 2 & 12 & 2 & 2 & 0 & 3 & I & B \\
\hline \% de casos confirmados & 6.9 & 18,0 & 14,3 & 8,7 & - & 17,6 & 4,7 & 28,6 \\
\hline \multicolumn{9}{|l|}{ Grupo $D:(n=71)$} \\
\hline Número de pacientes referidos & 18 & 24 & 3 & 2 & 1 & 10 & 2 & 13 \\
\hline Número de casos confirmados & 12 & 20 & 0 & 2 & 1 & 6 & 1 & 8 \\
\hline W de casos confirmados & 66.6 & 83,3 & - & - & - & 60.0 & - & 61,5 \\
\hline
\end{tabular}

Grupo A: Pacientes con síntomas atribuibes a inflamación de la vía urinaria alta o baja.

Grupo B: Pacientes referidos con fiebre sin causa aclarada por la anamnesis o el examen físico

Grupo C: Pacientes sin fiebre ni sintomas urinarios, referidos por sospecha indirecta de ITU (inapetencia, alteraciones del aspecto de la orina, dolor abdominal, etc).

Grupo D: Pacientes sin fiebre ni síntomas urinarios, referidos por ITU ya tratada. 


\section{Tabla 3}

Diagnóstico en 1275 pacientes evaluados por sospecha de infección urinaria en función de la edad y el sexo. Reiacion de varones:mujeres ( $V: M)$ en el total de casos confirmados en cada categoría de edad

\begin{tabular}{|c|c|c|c|c|c|c|c|}
\hline & $\operatorname{Sin}$ ITU & $\begin{array}{l}\text { ITU } \\
\text { previa }\end{array}$ & $\begin{array}{l}\text { Bact. } \\
\text { Asin. }\end{array}$ & $\begin{array}{l}\text { ITU } \\
\text { baja }\end{array}$ & $\begin{array}{l}\text { ITU } \\
\text { alta }\end{array}$ & $\begin{array}{c}\text { Total } \\
\text { con ITU }\end{array}$ & $v_{: M}$ \\
\hline 0 a 23 meses & 68 & 3 & 2 & 7 & 24 & 36 & \\
\hline Varones & 146 & 12 & 1 & 23 & 48 & 84 & $1: 2,3$ \\
\hline$\underset{\&}{\text { Mujeres }}$ & & 12,5 & 2,5 & 25,0 & $60,0^{2}$ & & \\
\hline \multicolumn{8}{|l|}{24 a 47 meses } \\
\hline Varones & 55 & 5 & 2 & 20 & 5 & 32 & \\
\hline Mujeres & 106 & $\sqrt{3}$ & 2 & 44 & 40 & 99 & $1: 3,1$ \\
\hline$\%$ & & 13.7 & 3,0 & 48.8 & 34,3 & & \\
\hline \multicolumn{8}{|l|}{48 a 71 meses } \\
\hline Varones & 18 & 3 & 0 & 4 & 5 & 12 & \\
\hline Mujeres & 62 & 10 & 0 & 53 & 29 & 92 & $1: 7,6$ \\
\hline$\%$ & & 12,5 & - & 54,8 & 32.7 & & \\
\hline \multicolumn{8}{|l|}{$>=72$ meses } \\
\hline Varones & 117 & 6 & 0 & 5 & 7 & 18 & \\
\hline Mujeres & 73 & 23 & 3 & 138 & 93 & 257 & $1: 14.4$ \\
\hline 50 & & 10,5 & 1,1 & 52,0 & 36,4 & & \\
\hline
\end{tabular}

1. Distribución porcentual de formas clínicas, entre los casos confirmados.

2. El riesgo de pielonefritis aguda fue significativamente más alto en menores de 23 meses que en las demás categorias de edad $\mathrm{OR}=3,3 ;(\mathrm{IC} 95 \%=2,1-5,3) ; \mathrm{p}=0,0000001$ (se excluye las infecciones urinarias previas).

ITU: infección urinaria.

sos con infección urinaria previa, fue tres veces mayor en los menores de 24 meses que en cualquiera de las otras categorías $[O R=3,3$; (IC 95\% $=2,1-4,3$ ), $\mathrm{p}=0,0000001]$.

Distribución de agentes etiológicos. La muestra de orina fue obtenida y procesada en la clínica de infección urizaria en 494 de los 555 pacientes que presentaban infeccion activa al momento de la referencia. En los restantes, por consultar de noche $o$ en días feriados, se tomó en el servicio de urgencias. Escherichia coli fue el microorganismo predominante en varones y mujeres; no obstante, la frecuencia de los agentes etiológicos varió significativamente en función del sexo y la edad de los pacientes tabla 4). El nivel anatómico de la infección urinaria, sin embargo, no se asoció a diferencias en la distribución de los microorganismos aislados (datos no mostrados). Los estudios de sensibilidad a antimicrobianos (Kirby Bauer) revelaron resistencia a ampicilina en $56 \%$ de las cepas de Escherichia coli, $39 \%$ de las cepas de Proteus y $100 \%$ de los aislamientos de Klebsiella. En el mismo orden, $39 \%, 16 \%$ y $22 \%$ de los microorganismos fueron resistentes a trimetoprim-sulfa-

\section{Tabla 4}

Frecuencia relativa de agentes etiológicos identificados en 494 episodios de infección urinaria, según sexo y edad de los pacientes

\begin{tabular}{lccc}
\hline & $\begin{array}{c}\text { Escherichia } \\
\text { coli }\end{array}$ & $\begin{array}{c}\text { Proteus } \\
\text { mirabilis }\end{array}$ & Klebsiella \\
\hline Varones ${ }^{2}, 3$ & & & \\
$\leq 23$ meses & 23 & 2 & 2 \\
24 a 47 meses & 11 & 13 & 0 \\
48 a 71 meses & 3 & 4 & 0 \\
$\geq 72$ meses & 7 & 4 & 1 \\
Mujeres & & & \\
523 meses & 51 & 1 & 1 \\
24 a 47 meses & 74 & 3 & 0 \\
48 a 71 meses & 68 & 3 & 3 \\
$\geq 72$ meses & 217 & 1 & 2 \\
\hline
\end{tabular}

1. Klebsiella preumoniae $=\mathrm{B} ;$ Klebsiella oxytoca $=1$

2. La frecuencia de gérmenes diferentes a Escherichia coli fue significativamente mayor en varones que en mujeres, en todos los estratos de edad. $O R=17,3$; (IC $95 \%=8,0-38,0) ; \mathrm{p}<10^{-6}$.

3. En varones, el aislamiento de gérmenes diferentes a Escherichia coli fue sigoificativamente más frecuente después de los 23 meses: $O R=5,3 ;($ IC95\% $=1,4-$ 21,4); $\mathrm{p}=0,009$.

4. En mojeres, la distribución de microorganismos no varió en función de la edad. 
metoxazol, y $35 \%, 16 \%$ y $22 \%$ a ambos antimicrobianos, 22 cepas de $E$. coli $(4,8 \%)$ eran resistentes a cefalosporinas orales, $1,3 \%$ a nitrofurantoína y $1,5 \%$ a gentamicina.

Frecuencia de recurrencias y análisis corre. lacional con variables clinicas. Quinientos ochenta y siete (587) pacientes resultaron elegibles para ingresar al protocolo de estudio y seguimiento, en tanto que otros 43 tenían controles previos en la unidad de nefrourología o provenían de sectores alejados del SSMN, por lo que fueron derivados inmediatamente después de comprobada la esterilidad de la orina, al término del tratamiento. Sesenta y cinco (65) niños elegibles dejaron de asistir a controles antes de completar el primer mes de seguimiento $(11,0 \%)$. El tiempo promedio de seguimiento de los 522 pacientes que adhirieron al programa fue 5,7 meses (mediana $=6$ meses, modo $=6$ meses.); 330 de ellos tuvieron períodos de observación iguales o inferiores a 6 meses, en tanto que los otros 192 fueron controlados por 7 a 18 meses. Las frecuencias de categorías diagnósticas, agentes etiológicos, edades y sexos, en los niños que abandonaron el seguimiento, fueron similares a las de los que permanecieron en controles; con respecto a estas variables, tampoco difirieron entre sí los grupos controlados por períodos inferiores, $0 \geq 7$ meses (datos no mostrados).

Ciento cuarenta y ocho de los 522 pacientes controlados $(28,4 \%)$ tuvieron al menos una recurrencia de infección urinaria después de la curación bacteriológica del episodio inicial. En general, los episodios de reinfección se presentaron en etapas tempranas del seguimiento: $71 \%$ antes del cuarto mes y $87,8 \%$ antes del séptimo mes de vigilancia; pese a ello, la frecuencia de recurrencias entre los pacientes controlados por períodos inferiores a 7 meses fue menor que la observada en los niños observados por tiempos más prolongados ( $22 \%$ vs $33 \%, \mathrm{p}=0,006)$. En 42 niños recurrentes se detect 6 dos o más episodios de reinfección. La distribución de los agentes etiológicos aislados en los cuadros de reinfección, y sus respectivos patrones de susceptibilidad a antimicrobianos, fueron similares a las encontradas en los episodios índice (datos no mostrados).

La razón recurrentes:no recurrentes en la muestra de niños controlados fue de $1: 2,52$ (148:374). El riesgo de recurrir no varió en función del sexo $(130 / 313,29,3 \%$ en niñas, vs $18 /$
$79,22,8 \%$ en varones), ni el nivel anatómico de la infección urinaria. E] análisis por estratos de edad, sin embargo, reveló que el riesgo de recurrir de los niños de 24 a 47 meses de edad fue aproximadamente un cuarto del observado en el conjunto de las demás edades. Por el contrario, el rango de 48 a 71 meses se asoció a un riesgo de recurrir 2,5 veces más alto que el de los otros grupos. Así mismo, la identificación de un microorganismo diferente a Escherichia coli (en el episodio inicial) se asoció a un riesgo de reinfección notablemente superior (2,5 veces), aun en el grupo de individuos de 24 a 47 meses. La estratificación de cualquiera de las variables antes enumeradas en función de un segundo factor (sexo/edad, sexo/germen, sexo/nivel de la infección urinaria, nivel/germen, etc.) no determinó diferencias en el riesgo de recurrir de los subgrupos resultantes; sin embargo, debido a que la representación del sexo masculino en la muestra fue francamente minoritaria $(15,1 \%)$, la separación por sexos frecuentemente resultó en pérdida de la significación estadística en el grupo de varones. La tabla 5 expone las razones de riesgo y el valor estadístico de la asociaciones entre cada una de las variables mencionadas y el evento "recurrencias".

Frecuencia de alteraciones de la ecografia y la uretrocistografia miccional y analisis correlacional con variables clínicas. En 415 de los 522 niños controlados se obtuvieron ambos estudios por imágenes; en 31 pacientes sólo se realizó ultrasonografía, y en otros ocho únicamente uretrocistografía miccional. Las causas de incumplimiento del estudio radiológico incluyeron abandono precoz del seguimiento o problemas previsionales que impidieron el financiamiento de los exámenes, y no determinaron diferencias en la distribución de variables como edad, sexo, diagnóstico y agente etjológico entre los niños con y sin estudio (datos no mostrados). En 40 de' $446(9,0 \%)$ ecografías se informó anomalía : la imagen de la vía urinaria. Las alterac: «s detectadas fueron: ectasia pielocaliciaria : 19 casos; hidronefrosis $=2$; asimetría del tamaño renal sugerente de cicatriz $=9$; nefropatía por reflujo $=2$; alteraciones de la forma vesical $=2$; alteraciones de las paredes vesicales $=2$; quiste renal $=1$; riñón único $=1$; riñon en herradura $=1$; litiasis renal $=1$. La frecuencia de alteraciones en la uretrocistografía fue $12,3 \%(52 / 424)$. Los hallazgos 


\section{Tabla 5}

Razones de riesgo para el evento "recurrencias" en función de variables clínicas, en 522 niños con infección urinaria y periodos variables de seguimiento

\section{Recurrencias}

\section{Si No OR (IC 95\%) p}

\section{Sexo}

Masculino

$18 \quad 61$

Femenitio

$130 \quad 313 \quad 1,4(0,8-2,6)$

0.29

Edades

$\begin{array}{llrll}>=23 \text { meses } & 29 & 78 & 0,9(0,6-1,5)^{2} & 0,84 \\ 24 \text { a } 47 \text { meses } & 11 & 92 & 0,2(0,1-0,5)^{2} & 0,000015 \\ 48 \text { a } 71 \text { meses } & 40 & 49 & 2,5(1,5-4,0)^{3} & 0,00022 \\ >=72 \text { meses } & 68 & 155 & 1,2(0,8-1,8)^{3} & 0,40\end{array}$

Germen

Escherichiacoli $116 \quad 294$

$\begin{array}{lllll}\text { Otro } & 19 & 19 & 2,5(1,2-5,2) & 0,0091\end{array}$

Nivel anatómico

Alto (Pielonefritis) $81 \quad 152$

$\begin{array}{lllll}\text { Bajo (Cistitis o } & 79 & 196 & 1,3(0.9-2.0) & 0,17\end{array}$ bacteriuria)

I. El valor de OR representa el riesgo para cada categoria de edad vs el resto en conjunto.

2. Menores de 24 meses vs 24 a 46 meses: $O R=3,1$ : (IC $95 \%=1,38-7,12) ; \mathrm{p}=0,0043$.

3. 48 a 71 meses $v 5 \geq 72$ meses: $O R=1.86$; $($ IC $95 \%=$ $1,08-3,18) ; p=0,021$.

anómalos fueron: reflujo vesicoureteral en 27 casos; alteraciones de la uretra $=10$; vaciamiento vesical incompleto $=10$; divertículos vesicales $=5$. Entre los niños que cumplieron con la realización de ambos estudios, $18,8 \%$ (78/415) tuvo alteraciones en al menos uno de ellos y $2,5 \%(10 / 415)$ en ambos.

La tabla 6 expone las razones de riesgo y los respectivos niveles de significacion de las asociaciones entre las variables clínicas y el evento "alteración en el estudio por imágenes". A diferencia de lo observado en el análisis anterior (recurrencias), el sexo masculino sí se asoció a mayor riesgo de alteraciones radiologicas, mientras que la edad no condicionó diferencias de riesgo para el grupo general, ni para los individuos de uno u otro sexo por separado. También en contraste con su comportamiento en re- lación a recurrencias, el hallazgo de un gemen diferente a Escherichia coli se asoció a una tendencia a mayor riesgo ( $O R=2,2)$, cercano a la significación estadística. En este caso, el análisis estratificado por examen revelo que esta tendencia derivo de la asociación entre el agente etiológico y el resultado de la uretrocistografía miccional: en efecto, los pacientes infectados por microorganismos diferentes a $E$. coli presentaron un riesgo cuatro veces más alto de CUMS anormal 18 de 25 niños con germen diferente de $E$. coli tuvieron CUMS alterado, en contraste con 36 de 340 niños infectados por $E$. coli; OR $=3,9 ;($ IC $95 \% 1,5-10,7) ; \mathrm{p}=0,004]$, en tanto que el agente etiológico no influyó en el riesgo de alteración ultrasonográfica $[2 / 26$ vs $30 / 351$ OR $=0,9 ;(\mathrm{IC} 95 \%=0,3-4,1)]$.

Asociación de ambos eventos. La correlación de los dos eventos de interés clínico entre sí revelo un riesgo de recurrencias cercano al doble para los pacientes con estudio alterado, res-

\section{Tabla 6}

Razones de riesgo para el evento "estudio alterado" en funcion de variables clínicas, en 415 niños con infección urinaria evaluados con ultrasonografía abdominal y uretrocistografía miccional seriada

\begin{tabular}{|c|c|c|c|c|}
\hline & $\begin{array}{c}\text { Estudio } \\
\text { Sí }\end{array}$ & $\begin{array}{c}\text { alierado } \\
\text { No }\end{array}$ & OR (IC 95\%) & $\mathbf{p}$ \\
\hline \multicolumn{5}{|l|}{ Sexo } \\
\hline $\begin{array}{l}\text { Masculino } \\
\text { Femenino }\end{array}$ & $\begin{array}{l}17 \\
61\end{array}$ & $\begin{array}{r}41 \\
296\end{array}$ & $2,0(1,0-3,9)$ & 0.04 \\
\hline \multicolumn{5}{|l|}{ Edades $^{1}$} \\
\hline $\begin{array}{l}>=23 \text { meses } \\
24 \text { a } 47 \text { meses } \\
48 \text { a } 71 \text { meses } \\
>=72 \text { meses }\end{array}$ & $\begin{array}{l}16 \\
17 \\
19 \\
26\end{array}$ & $\begin{array}{r}69 \\
67 \\
49 \\
152\end{array}$ & $\begin{array}{l}1,0(0,5-1,9) \\
1,1(0,6-2,1) \\
1,9(0,9-3,6) \\
0,6(0,4-1,1)\end{array}$ & $\begin{array}{l}0,88 \\
0,82 \\
0,052 \\
0,77\end{array}$ \\
\hline
\end{tabular}

Germen

$\begin{array}{lrrrr}\text { Escherichia coli } & 59 & 273 & & \\ \text { Otro } & 8 & 17 & 2,2(0,8-5,7) & 0,07\end{array}$

Nivel anatónico

\begin{tabular}{|c|c|c|c|}
\hline Alto (pielonefritis) & 46 & 142 & $2,0(1,2-3,5)$ \\
\hline bacteriyria) & 28 & 175 & \\
\hline
\end{tabular}

I. El valor de OR representa el riesgo para cada categoría de edad ts el resto en conjunto. 
pecto a los que tuvieron ambos exámenes normales: 32 de $\operatorname{los} 78$ niños $(41 \%)$ con ultrasonografía o uretrocistografía anormal presentaron recurrencias durante el seguimiento, en contraste con 94 de $337(27,9 \%)$ con estudio normal $[\mathrm{OR}=1,8 ;(\mathrm{IC} 95 \%=1,04-3,0)]$. Como se deduce de examinar los intervalos de confianza, nuevamente el análisis de las recurrencias y cada examen por separado mostró que la asociación dependió casi exclusivamente de la presencia de alteraciones en la uretrocistografía (24 recurrentes entre 52 niños con este examen alterado, ante 102 en 363 si era normal; $O R=2,2$; (IC $95 \%=1,16-4,1$ ); $p=0.012$ ], mientras que las anomalías ultrasonográficas no se asociaron a mayor riesgo de recurrir [13 niños con recurencias de 36 con examen alterado, ante 113 de 339 con éste normal; $O R=1,1 ;$ (IC 95\% $=0,46$ $-2,2), p=0,88]$.

\section{Comentario}

E1 diagnóstico de presunta infección urinaria es un problema que impacta fundamentalmente en el primer nivel de la atención médica. A djfcrencia de la mayoría de las causas de consulta ambulatoria, la sospecha clínica de estas enfermedades sólo puede ser resuelta con estudios de labotarorio, exigencia inherente a la definición (bacteriologica) de la enfermedad. Lo anterior. asociado a dificultades para acceder al laboratorio desde el nivel primario, fue la causa de importantes deficiencias en la asistencia de los niños con infección urinaria en una muestra retrospectiva previa ${ }^{8}$. Este trabajo fue concebido con la intención de ensayar un modelo de lo que estimamos debe ser el rol del primer njvel de atención frente a los niños con estas enfermedades: sospecha clínica amplia; estudio de laboratorio oportuno; diagnóstico bacteriológico en todos los casos; tratamiento acorde al nivel anatómico de la enfermedad y a la susceptibilidad antimicrobiana del agente causal; control bacteriológico en todos los episodios tratados y derivación selectivo de los pacientes a las unidades de atención especializada, de acuerdo al resultado del seguimiento y el estudio por imágenes. Al mismo tiempo, la clínica de infección urinaria se abstuvo intencionalmente de profundizar en el diagnóstico y tratamiento de situaciones complejas (como trastornos urodiná- micos, de la función renal, etc.), en las cuales es deseable la intervención inmediata de los especialistas.

La incidencia general y las tasas de ataque por edad y sexo son comparables a los informados en otros países ${ }^{1.4}$, y refuerzan la necesidad de situar a estas enfermedades entre aquellas cuya atención médica requiere ser planificada con una perspectiva de Salud Pública. Por otra parte, esta muestra contrasta de manera notable con lo observado recientemente en la misma comunidad $^{8}$. Este programa se acompañó de un aumento cercano al doble en la tasa de incidencia de infección urinaria en la población adscrita, efecto que se extendió a la población cuyo contacto con la clínica de infección urinaria se estableció exclusivamente a través de las consultas a la unidad de emergencias del hospital. Puesto que las tasas de estas enfermedades son reconocidamente estables en el tiempo ${ }^{1-3}$, este aparente aumento sugiere subdiagnóstico de infección urinaria en pacientes ambulatorios, corregido (quizá parcialmente) por intervenciones que contribuyeron a estimular la sospecha en atención primaria y de urgencias, mejor acceso al diagnóstico de laboratorio y realimentación oportuna con información hacia los sitios de pesquisa. El programa se asoció también a reducción del riesgo de hospitalización de los pacientes con infección urinaria, con respecto al observado en la muestra retrospectiva ${ }^{8}$. Sin pretender establecer una relacion de causalidad (por tratarse de observaciones extemporáneas), es atendible suponer que, en cierta medida, una atención más expedita y acuciosa de los pacientes haya contribuido.

Aparte de la información epidemiológica previamente analizada, esta experiencia ilustra sobre la probabilidad de confirmacion del diagnóstico en diferentes situaciones de sospecha clínica, la distribución de los agentes etiológicos, y sus actuales patrones de susceptibilidad a antimicrobianos. Esios datos, sumados a los resultados de pruebas rápidas de rastre ${ }^{16}$, deberían ser de utilidad en la práctica ambulatoria.

Numerosos factores confluyen para que la decisión de hacer estudios de la anatomía y función de la vía urinaria y de mantener al paciente en control para detectar la aparición nuevos episodios sea compleja en la atención de niños con infección urinaria. La variedad de enfermos es amplia. Aunque en la mayoría la enfermedad no 
se acompaña de los eventos señalados, cuando ellos ocurren pueden representar una amenaza importante para la salud. Por último, los estudios radiológicos y el seguimiento incluyen procedimientos invasivos y recursos caros. Hasta Ia fecha, en Chile se aplican criterios de selección de otros lugares que no parecen constituir una respuesta universal al problema ${ }^{17-20}$. En consecuencia, para analizar el comportamiento local de las variables clásicamente asociadas a mayor riesgo recurrencias o alteraciones nefrourológicas subyacentes, los niños de este estudio fueron investigados y seguidos sin restricciones de edad ni sexo, con la sola condición de no haber sido sometidos previamente a estudios similares. Esto explica que la frecuencia de alteraciones radiologicas descrita pueda parecer inferior que en otras series, generalmente integradas por pacientes seleccionados en función de alguna condición de riesgo $0^{21-25}$. Antes de discutir las observaciones derivadas de este procedimiento es necesario reconocer las limitaciones que podrían afectar la interpretación de las mismas. Primero, la representación de los varones en la muestra fue minoritaria (lo cual reproduce el patrón de distribucion por sexos de esta enfermedad) $)^{1 \cdot 3.9}$; consecuentemente, el poder de la muestra de ellos fue, con frecuencia, insuficiente para detectar significación en diferencias de riesgo que pudieron haber tenido relevancia clínica. Por otra parte, el protocolo de manejo clínico preestableció, por razones éticas y prácticas, que los pacientes con recurrencias o alteraciones del estudio radiologico serían derivados a la unidad de nefrourología tan pronto estos problemas fueran detectados. Dicha conducta, y probablemente otros factores capaces de modificar la adherencia de los pacientes al seguimiento, influyeron en que la duración de las observaciones fuera variable. Sin embargo, aun cuando en esta muestra el tiempo de seguimiento influyó significativamente en la probabilidad de detectar recurrencias, la frecuencia general de estos eventos fue comparable a la descrita en seguimientos más prolongados ${ }^{1-4,14,26,27}$. Por último, es necesario reconocer que un grupo de niños elegibles no adhirio al programa de estudio y seguimiento, aun cuando ellos no difirieron de los que cumplieron el protocolo en la distribucion de las variables independientes analizadas. Pese a estas limitantes, esta experiencia permitio afirmar que la identificación de un germen diferente a Escherichia coli en el episodio índice involucra riesgos mayores de reinfección y de alteraciones en la uretrocistografía, y que el sexo masculino y la infección alta se asocian con mayor riesgo de alteraciones radiologicas. Por último, el análisis permite documentar que ambos eventos se presentan en un mismo paciente con una frecuencia superior a la atribuible al azar.

Algunas observaciones derivadas de lo anterior merecen consideracjón especial. En primer término, el riesgo de recurrencia de los individuos entre 24 y 47 meses de edad fue significativamente inferior al de cualquier otra categoría, hecho no descrito en la literatura. ¿Qué fenómeno biológico podría ser invocado para dar cuenta del peculiar efecto de "proteccion" sobre el riesgo de recurrencias asociado a este estrato etareo? Como una explicación posible postulamos que a esta edad concurren circunstancias transitorias que favorecen la instalación de infección urinaria en pacientes sin otros factores predisponentes; por ejemplo, el entrenamiento en el control esfinteriano (rectal y vesical) podría ser causa de retención urinaria y de sobrecrecimiento bacteriano en la vejiga. Asimismo, en las niñas pequeñas son frecuentes métodos de aseo, después de defecar, que facilitan la colonización periuretral. Puesto que estos factores son transitorios, podrían favorecer la infección urinaria a esta edad y que en ella el riesgo de recurrir sea inferior al de otras categorías, afectadas por mecanismos predisponentes de carácter más permanente. Otra observación interesante, con sentido biológico, fue la asociación entre alteraciones de la uretrocistografía miccional y recurrencias, y su ausencia entre anomalías ecográficas y dicho evento. Analizados individualmente, los pacientes con reinfección y alteración radiológica resultaron mayoritariamente afectados por anomalías condicionantes de ectasia en la vía urinaria baja (malformaciones uretrales, vaciamiento vesical incompleto y divertículos vesicales), con reconocida capacidad de favorecer las recurrencias ${ }^{1,14,26.27}$. En el mismo sentido, un análisis más preciso (estratificado por examen) del riesgo de estudio radiológico alterado observado en los pacientes infectados por gérmenes diferentes a $E$. coli puso en evidencia que esta variable se asoció, en realidad, a un riesgo mayor de uretrocistografía anormal, no así de ultrasonografía, con hallaz- 
gos patológicos. En estos casos, las anomalías radiológicas correspondieron preferentemente a disfunciones como el reflujo, que teóricamente puede facilitar la localización alta, aun por gérmenes con escasa capacidad de adherencia al uroepitelio $^{12,13}$.

Las información expuesta es aplicable en el manejo individual de los niños con infección urinaria y en la planificación de la atención médica de estas enfermedades. Este es tarrbién un primer intento local por resolver el problema de predecir los riesgos de recurrencias y anomalías nefrourológicas, a cuyo respecto preferimos diferir nuestras conclusiones hasta disponer de datos que derivarán de estudios adicionales en curso; por el momento, este análisis permite una orientación preliminar hacia la identificación de los niños con infección urinaria que concentran los mayores riesgos de presentar los eventos de importancia clínica.

\section{Resumen}

Entre marzo de 1992 y febrero de 1993, en el Servicio Salud Metropolitano Norte (SSMN) se desarrolló un programa para mejorar la calidad de la atención médica y estudiar la epidemiología de las infecciones del tracto urinario (infección urinaria) en menores de 15 años. El programa incluyó la derivación de los casos sospechosos desde 7 de los 14 consultorios periféricos y la Unidad de Emergencias del servicio, a una unidad clínica habilitada en el Hospital Roberto del Rfo. A la fecha, la población $\leq$ de 15 años del SSMN era de 188329 habitantes, 108221 de los cuales pertenecían a los siete consultorios adscritos al programa. Los pacientes referidos a la clínica de infección urinaria fueron estudiados y tratados en protocolos estândar y seguidos mensualmente. Se indicó ultrasonografía abdominal y uretrocistografía miccional a todos los niños con infección urinaria $\sin$ estudios previos. En 630 de los 1275 niños referidos se confirmó la sospecha clínica de infección urinaria; la tasa de ataque de la enfermedad fue significativamente mayor en la población adscrita $(3,7 / 1000)$ que en la no adscrita al programa $(2,7 / 1000, \mathrm{p}<0,0003)$. La pielonefritis aguda fue más frecuente en menоres de 24 meses que en otras edades $(O R=3,3$; IC $95 \%=2,1-5,3) ; \mathrm{p}<0,0000001)$. E. coli fue el microoranismo predominante en anbos sexos, pero e] aislamiento de otros gérmenes fue significativamente más frecuente en varones $(\mathrm{OR}=17,3 ;$ IC $95 \%=8,0-38,0) .148$ de 522 $(28,4 \%$; IC $95 \%=24,5-32,3)$. Ciento cuarenta y ocho niños controlados tuvieron al menos una recurrencia de infección urinaria, $87,8 \%$ de ellas ocurrió antes del séptimo mes de seguimiento. El tramo de 48 a 71 meses de edad y los gérmenes diferentes a $E$. coli se asociaron a mayor riesgo de recurrir: $O R=2,5$; $($ IC $95 \%=1,5$ $4,0)$ y $O R=2,5$; (IC $95 \%=1,2-5,2)$, respectivamente. La pielonefritis aguda y el sexo masculino se asociaron a mayor riesgo de alteraciones en el estudio radiologico (OR $=2,0$; IC $95 \%$ $=1,03-3,9$ y $\mathrm{OR}=2,0, \mathrm{IC} 95 \%=1,2-3,5)$, respectivamente.

(Palabras clave: vía urinaria, infección.)

\section{Agradecimientos}

A los médicos encargados de la atención pediätrica ambulatoria en el Servicio de Salud Metropolitano Norte. y al financiamiento otorgado por el Ministerio de Salud de Chile, a través de PMI/APS-AID. A los médicos profesores Gastón Duffau e Isidoro Horwitz por la revisión del original.

\section{Referencias}

1. Sobet $I D$, Kaye $D$ : Urinary tract infections. En: Mandell GL, Douglas RG, Benpett JE (eds). Principles and Practice of Infectious Diseases. (Tercera edición). New York. John Willey \& Sons, 1990: Chap 58: 582-611.

2. Stull TL, LiPuma JV: Epidemiology and natural history of urinary tract infections in children. Med Clin North Am 1991; 75: 287-297.

3. Wimberg $J$, Andersen $H Y$, Bergstrom $T$ : Epidemiology of symptomatic urinary tract infections in childhood. Acta Paediatr Scand 1974; 63(S252): SI-S20.

4. Ginsberg CM, Mc Cracken GH: Urinary Iract infections in young infants. Pediatrics $1982 ; 69: 409$. 412.

5. Tappin DM. Murphy AV, Mocan H, Shaw R, Beantie TJ. Mcallister TA, Macknzie JR: A prospective study of children with first acute symptomatic E.coll urinary tract infection. Acta Paediatr Scand 1989: 78: 923929.

6. Jacobson SH, Eklof $O$. Lins LE, Wikstad J, Winberg $J$ : Long term prognosis of post-infectious renal scarring in relation to radiological findings in childbood. A 27 year follw up. Ped Nephrol 1992; 6: 19-24.

7. Smellie J: Reftections on 30 yeats of treating children with urinary tract infections. J Urol 1991; 146: 665668. 
8. Lagos $R$, Becerra $M_{1}$ Abarca E: Infección del tracto urinario en niños del Area Norte de Santiago: aspectos clínicos y epidemiologicos. Rev Chil Pediatr 1992; 63: 18-25.

9. Bergstron $T$ : Sex differences in childhood urinery rract infections. Arch Dis Child 1972; 47: 227-232

10. Berg UB, Johanson $S B$ : Age as a main determinant of renal functional damage in urinary tract infections. Arch Dis Child 1983; 963-969.

1. Sheldon CA. Gonzälez R: Differentiation of upper and lower urinary tract infections. How and when? Med Clin North Am 1984; 68: 321-333.

12. Lomberg $H$, De Man P. Svamborg C: Bacterial and host determinants of renal scarning. APMIS 1989; 97: 193-199.

13. De Man P, Cleaseon I, Johanson I, Jodal U, Svanborg Eden $C$ : Bacteria attachment as a predictor of renal abnormalities in boys with urinary tract infections. J Pediatr 1989; 115: 915-922

14. Jones KV, Asscher AW: Uninary tsact infections and vesico ureteric reflux. In: Edelman CM Jr.(Ed) Pediatric kidney disease. Second Edition. Little, Brown and Company, Boston, Toronto, London. 1992: 19431992.

15. Schsselman $J f$ : In: Case control studies. NY, Oxford University Press, 1982.

16. Lages 8 . Carter J, Herrera P: Utilidad de una tira reactiva y del aspecto macroscópico de la orina para descartar la sospecha de infección del tracto urinario en niños ambulatorios. Rev Chil Pediatr 1994; 65: 88-94.

17. Hellerstein S, Wald ER, Wimberg Ji Consensus: Roentgenographic evaluation of children wilh urinary tract infections. Ped Inf Dis 1984; 3: 291-293.
18. Kennedy JC. Abott GD, Mc Rae CV, Maling TMJ: A protocol for investigation of infants and children presenting with urinary tract infections. En: Bailey RR (Ed). Second Symposium on Reflux Nephropathy. Christchurch. New Zaeland, 1991. Printing Services 1991: 76.

19. Ekart P. Broyer $M$ : Nephropathie du reflux. Rev Prat (Paris) 1992; 42: 447-451.

20. Boiley RR: Vesico-ureteric reflux and reflux nephro. pathy. Kid Int 1993; 44(S42): S80-S85.

21. Mc Cracken GH: Diagnosis and management of acute urinary tract infections in infants and children. Ped Infect Dis 1987; 6: 107-112.

22. Smellie JM, Hodson CJ. Edwards D. Normand JCS; Clinical and radiological features of urinary tract in. fections in childhood. Br Med I 1964; 5419: 1222. 1226.

23. Smellie JM. Normand JCS, Katz G: Children with urinary tract infections. A comparison of those with and without vesicoureteric reflux. Kid Int 1981; 20: $717-722$

24. Moenne $X$, Barria $M$. Samith S. Escaffi A, Soto $C$ : Diagnóstico por imagen en infección urinaria: Revisión de un año. Rev Pediatría (Santiago), 1992; 35: 15-19.

25. Hansion S. Hjalmans $K$, Jodal $U$, Sixt $R$ : Lower urinary tract infections in girls with untreated asymptomatic or covett bacteriuria. J Urol 1900; 143: 333-335.

26. Feld $L G$, Greefield $S P$, Ogra $P L$ : Urinary tract infections in infants and children. PLR 1989; 11:71-77.

27. Mannhurl $W$, Schofer $O$, Schulte-Wissermann $H$ : Pathogenic factors in recurrent urinary tract infections and renal scarr formation in children. Eur $\mathrm{J}$ Pediats $1986 ; 154: 330-336$. 